\title{
Frontal Meningoencephalocele: Changing Trends
}

\author{
${ }^{1}$ Ashok K Gupta, ${ }^{2}$ Sourabha K Patro, ${ }^{3}$ Varun Nabh
}

\begin{abstract}
Frontal sinus defects involving the posterior table has always been challenging for the otolaryngologists. It traditionally involved open approaches like osteoplastic approach for the repair of defects or fractures involving the posterior table of frontal sinus. Better instrumentation, technique, and experience have increased the feasibility of endoscopic repair of frontal sinus skull-base defects. With the increased possibilities of endoscopic approach and instrumentation for the frontal sinus, an endoscopic repair of a posterior table defect with a meningoencephalocele in a long standing post-traumatic case has been described
\end{abstract}

Keywords: Meningoencephalocele, Frontal, Repair, Endoscopic.

How to cite this article: Gupta AK, Patro SK, Nabh V. Frontal Meningoencephalocele: Changing Trends. Clin Rhinol An Int J 2014;7(3):125-129.

\section{Source of support: Nil}

Conflict of interest: None

\section{INTRODUCTION}

Frontal sinus defects involving the posterior table has always been challenging for the otolaryngologists. It traditionally involved open approaches like osteoplastic approach for the repair of defects or fractures involving the posterior table of frontal sinus. ${ }^{1}$ This was due to the difficulty in accessing these areas endoscopically. Progressive advancement of endoscopic sinus surgery has led to the possibility of approaches which are less invasive.

Better instrumentation, technique, and experience have increased the feasibility of endoscopic repair of frontal sinus skull-base defects. Many authors like Anverali et al have tried to repair the frontal sinus defects by increasing the exposure by performing modified lothrop procedures. ${ }^{2}$ The external procedures, when performed in post-traumatic cases many a times involve cranialization or obliteration of the sinus if the outflow tract or the recess

\footnotetext{
${ }^{1}$ Professor, ${ }^{2}$ Senior Resident, ${ }^{3}$ Resident

${ }^{1-3}$ Department of Otolaryngology and Head and Neck Surgery Postgraduate Institute of Medical Education and Research Chandigarh, India
}

Corresponding Author: Ashok K Gupta, Professor Department of Otolaryngology and Head and Neck Surgery Postgraduate Institute of Medical Education and Research Chandigarh, India, Phone: 09914209763, Fax: +91-1722744401, e-mail: drashokpgi@hotmail.com area is also involved in the fractures. However in cases with defects of the posterior table of frontal sinus which may or may not be associated with an encephalocele does not need a cranialization.

Open approaches in the frontal sinus involves cosmetically unacceptable incisions and when not obliterated is also associated with inherent risks of future episodes of sinusitis due to improper drainage of the frontal sinus. ${ }^{3}$ These risks also exist in the endoscopic technique however the disadvantages of using external approach with a bicoronal incision like paresthesias, scarring, alopecia and infective complications ${ }^{4}$ are reduced markedly with endoscopic approaches making it more functionally and cosmetically acceptable. Inspite of the traditional thinking about posterior table defects as a contraindication for endoscopic repair, authors have tried endoscopic repair in the literature to avoid the complications of external approaches. 5,6

With the increased possibilities of endoscopic approach and instrumentation for the frontal sinus, the senior author performed an endoscopic repair of a posterior table defect with a meningoencephalocele in a long standing post-traumatic case. We present the case report of the above.

\section{CASE REPORT}

An 18-year-old boy was referred from the department of surgical neurology for any possible surgical intervention in this tertiary care center. The patient had and history of fall from a height of 10 feet 10 years back. After which he developed post-traumatic CSF rhinorrhea. For which he was treated conservatively. After 2 weeks of conservative management the rhinorrhea stopped and patient was discharged from the hospital. In the last 10 years he had never complained of recurrence of CSF leak from the nasal cavity. However he developed four episodes meningitis in the last 10 years which was treated conservatively by the department of neurology in each of the episode. The initial two episodes were in the first year after the trauma. After the initial 2 episodes the patient remained asymptomatic. He again presented with the third episode of meningitis 6 months back and was again managed conservatively and was diagnosed to have a frontal sinus defect with an encephalocele. He again presented to the emergency 8 weeks back with complains of headache, fever and was diagnosed as 
meningitis by CSF analysis. Followed by 4 th episode the patient was referred to us for any possible endoscopic repair of the meningoencephalocele and the defect of the post table of the frontal sinus.

The patient was treated conservatively with 3 weeks of IV antibiotic and was followed up for another 3 weeks to see for any signs of meningitis. Followed by which an nasal endoscopy was done and was found to be having an encephalocele in the right nasal cavity reaching up to the middle meatus. An MR cisternography was done see for any site of leak and for estimating the defect. It was found that the patient was having and encephalocele into the nasal cavity with a defect in the frontal sinus in the posterior table (Figs 1A to D). The patient was planned for endoscopic repair of the defect to avoid any future episodes of meningitis.

All required workup for general anesthesia including hemogram, coagulogram, serum electrolytes, renal function tests, ECG and chest X-ray was done and patient was taken for endoscopic repair of the defect.

There was an encephalocele present in the middle meatus and on further exposure it was found to be occupy- ing whole of the frontal recess. The encephalocele was separated from the surrounding mucosa and was found to be originating from the posterior table of frontal sinus with a defect of approximately $1^{*} 1.5 \mathrm{~cm}$ (Figs $2 \mathrm{~A}$ and D). The meningocele was cauterized with bipolar diathermy and the resected. And the defect was identified with the bony margins all around. This defect was the closed with 4 layer technique using muscle, fat, cartilage followed by a layer of fascia lata harvested from the thigh (Figs 3A to D). Adequacy of the closure was checked with intraoperative valsalva maneuver.

\section{DISCUSSION}

Post-traumatic CSF leaks usually resolves with conservative management with bedrest and/or a lumbar subarachnoid drain. ${ }^{7}$ Post-traumatic leaks consists of 80 to $90 \%$ of acute CSF leaks. ${ }^{8}$ Only those cases which does not relieve with conservative management after 3 weeks are considered for repair of the leaks in cases where there is no evidence of meningitis, else IV antibiotic therapy is continued for 3 weeks till signs and symptoms of meningitis gets relieved.
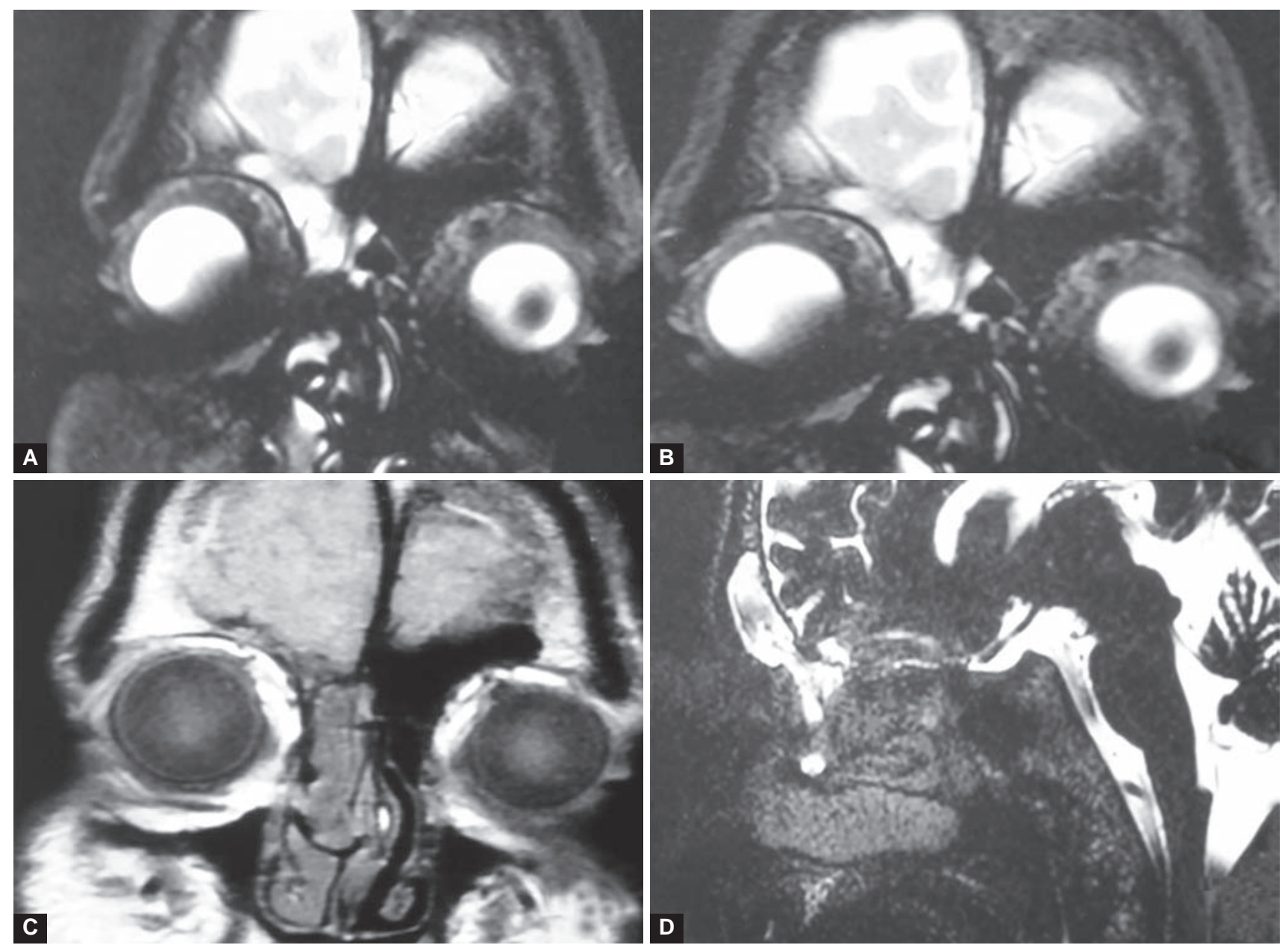

Figs 1A to D: (A and B) Coronal T2 images, (C) coronal T1 images and (D) showing sagittal T2 weighted images of the patient showing a defect in the posterior table of frontal sinus and prolapsing meningoencephalocele 

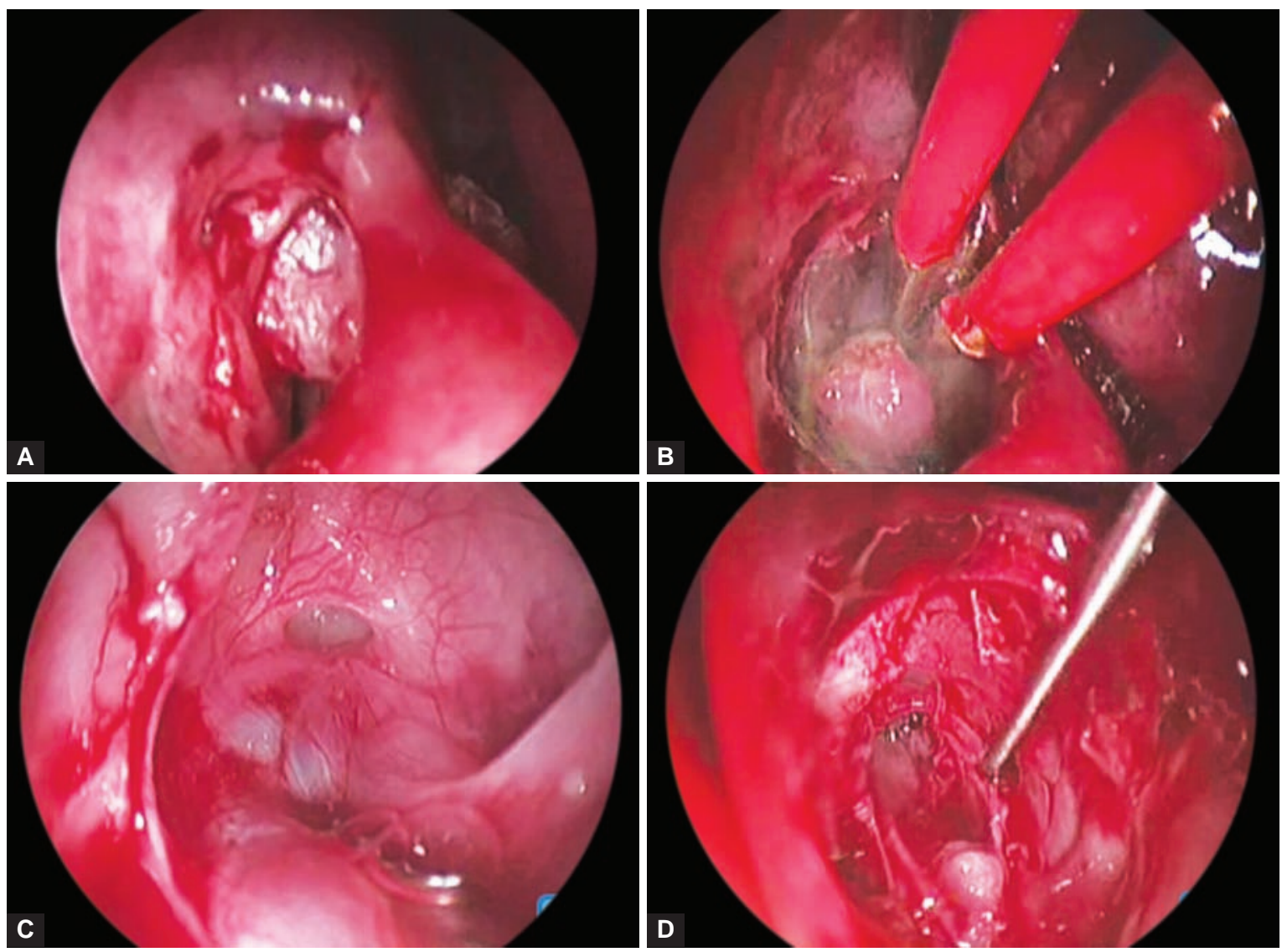

Figs 2A to D: (A) Endoscopic view of the encephalocele, (B) bipolar diathermic cauterization of the base of the encephalocele, (C) defect in the skull base in the posterior table of frontal sinus after resection of the encephalocele sac and (D) resecting the surrounding mucosa of the defect to delineate the bony margin
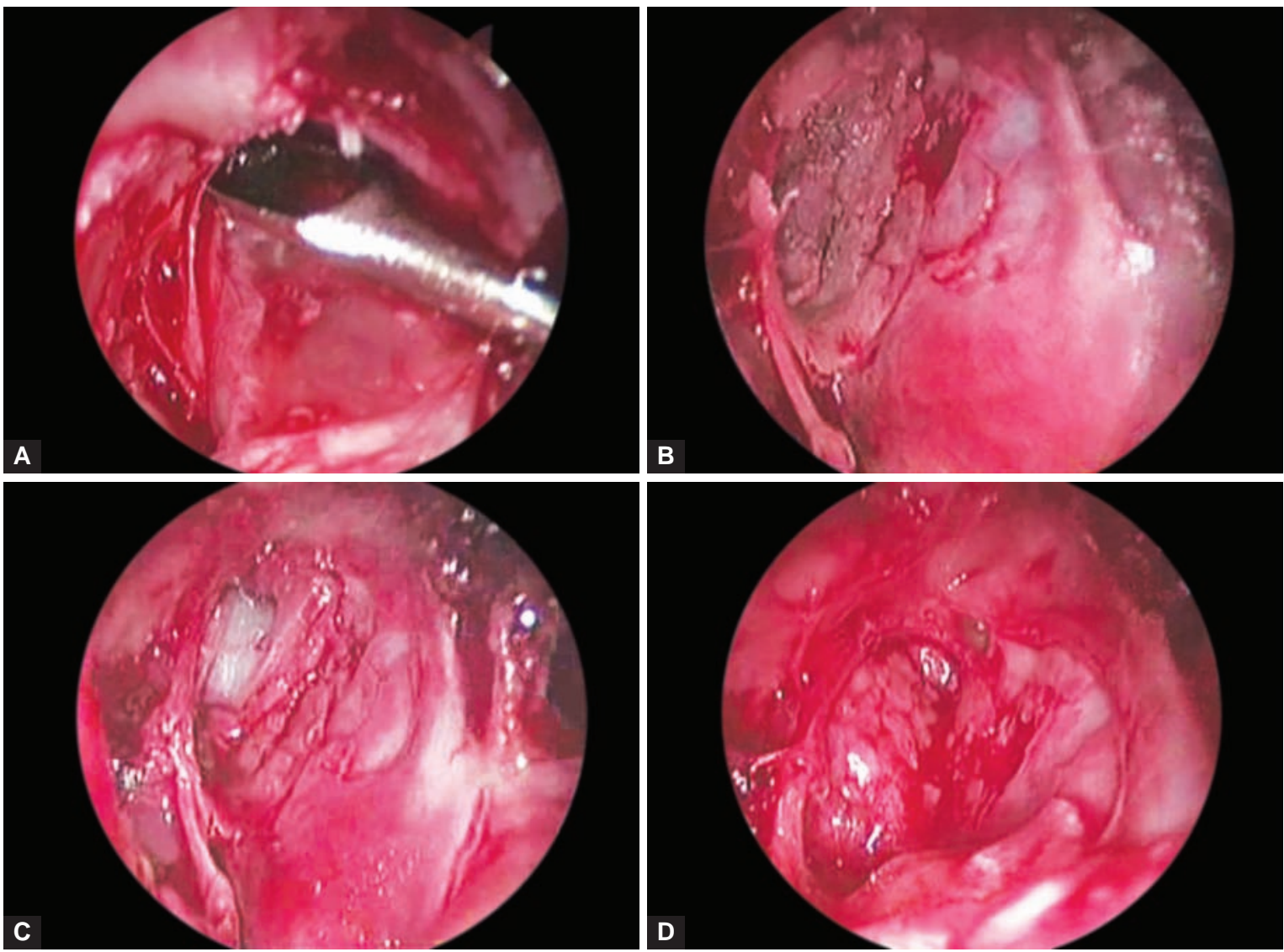

Figs 3A to D: (A) Removal of the mucosa surrounding the defect, (B) closure of the defect by plugging smashed muscle, (C) cartilage positioning and obliteration of the defect, (D) final closure of the defect with fascia and septal mucosal flap 
Traumatic CSF leaks are many a times associated with risks of meningitis and other infective complications like epidural abscess. ${ }^{9}$ Hence, along with bedrest and/or lumbar drain, prophylactic antibiotic therapy in anti meningitic doses is advised in post-traumatic leaks. Similar to the literature, in our case the patient relieved of symptoms with conservative management when the patient initially presented to our OPD 10 years back.

In our case the patient though got relieved from the initial symptom of CSF rhinorrhea with conservative management, however developed recurrent episodes of meningitis which is reported in the literature where there in a persistent leak or a meningoencephalocele in the nasal cavity getting exposed to the nasal bacterial flora repeatedly. ${ }^{8,10}$

In the initial days when endoscopic procedures were in the stage of infancy, most of the repairs of skull base defects were repaired with open craniotomy techniques using pericranial flaps or fascia grafts. ${ }^{11}$ However, improved endoscopic techniques, use of endoscopic instrumentation has led to increased use of endoscopic techniques for repair of the defects of the anterior skull base. ${ }^{12,13}$

Even in the era of endoscopic repair of anterior skull base defects frontal sinus posterior table defects have been traditionally considered as a contraindication for endoscopic repair. However, the open approaches involve cosmetically unacceptable scars, frontal lobe retraction and complications like alopecia and paresthesia. The transnasal endoscopic approach for posterior table fractures is technically difficult procedures due to lack of proper instrumentation and due to lateral extension leading to lack of exposure for surgical work in the frontal sinus. ${ }^{5,14}$ However, the endoscopic technique helps to avoid the morbidity of external approaches (e.g. coronal or brow incisions) and associated changes in cosmesis. This minimally invasive approach is capable of maintaining patency of the frontal sinus outflow tract and allows endoscopic surveillance during the postoperative period to see for development of any complications, such as recurrence of the CSF leak or closure of the frontal sinus. Maintaining patency of the frontal sinus is of great concern to avoid chances of subsequent mucocele development. In cases of osteoplastic repair with cranialization where the mucosa of the sinus is removed, the surgeon must make an intraoperative decision regarding maintaining patency of the frontal sinus space. Hence, clinical follow-up is recommended for all patients of frontal sinus post table repair regardless of approach (external or endoscopic) to ensure long termpatency of the frontal sinus or, in the case of obliteration or ablation of the sinus, development of a mucocele. Hence, the follow-up requirements are more or less similar for both the approaches used for frontal sinus defect. The feasibility of repair of posterior table defects were nicely studied in cadaver by Eloy et $\mathrm{al}^{15}$ and Batra et al. ${ }^{16}$ Few reports of repair similar defects has been reported earlier in literature by authors like Anverali et $\mathrm{al}^{2}{ }^{2}$ Jones et $\mathrm{l}^{14}$ and Eloy et al. ${ }^{6}$ Basing on this, we attempted the repair of the defect using endoscopic technique in this case along with resection of the mucocele and could find that there was no technical difficulty in the feasibility in repairing the posterior table defect.

\section{CONCLUSION}

Frontal sinus defects of posterior table were traditionally being considered as a contraindication for endoscopic repair. However, with the improved and angled endoscopes and improved instrumentation it is feasible to repair the defects of the posterior table even the lateral ones. Hence, posterior table defects of the frontal sinus should not be considered as a contraindication for endoscopic repair anymore.

\section{REFERENCES}

1. Rice DH. Management of frontal sinus fractures. Current opinion in otolaryngology and head and neck surgery 2004;12(1):46-48.

2. Anverali JK, Hassaan AA, Saleh HA. Endoscopic modified Lothrop procedure for repair of lateral frontal sinus cerebrospinal fluid leak. J Laryngol Otology 2009;123(1):145-147.

3. Chaaban MR, Conger B, Riley KO, Woodworth BA. Transnasal endoscopic repair of posterior table fractures. Otolaryngology-Head and Neck Surg: An Acad Otolaryngol-Head Neck Surg 2012;147(6):1142-1147.

4. Strong EB, Buchalter GM, Moulthrop TH. Endoscopic repair of isolated anterior table frontal sinus fractures. Archives Facial Plastic Surg 2003;5(6):514-521.

5. Woodworth BA, Schlosser RJ, Palmer JN. Endoscopic repair of frontal sinus cerebrospinal fluid leaks. J Laryngol Otology 2005;119(9):709-713.

6. Eloy JA, Mady LJ, Kanumuri VV, Svider PF, Liu JK. Modified subtotal-Lothrop procedure for extended frontal sinus and anterior skull-base access: a case series. Int Forum Allergy Rhinol 2014.

7. Rice DH. Cerebrospinal fluid rhinorrhea: diagnosis and treatment. Current Opinion in Otolaryngol Head Neck Surg 2003;11(1):19-22.

8. Kerr JT, Chu FW, Bayles SW. Cerebrospinal fluid rhinorrhea: diagnosis and management. Otolaryngol Clinics North America 2005;38(4):597-611.

9. Bernal-Sprekelsen M, Bleda-Vazquez C, Carrau RL. Ascending meningitis secondary to traumatic cerebrospinal fluid leaks. Am J Rhinol 2000;14(4):257-259.

10. Pappas DG Jr, Hammerschlag PE, Hammerschlag M. Cerebrospinal fluid rhinorrhea and recurrent meningitis. Clinical Infectious Diseases 1993;17(3):364-368.

11. Tiwari P, Higuera S, Thornton J, Hollier LH. The management of frontal sinus fractures. J Oral Maxillofac Surg 2005; 63(9):1354-1360. 
12. Lanza DC, O'Brien DA, Kennedy DW. Endoscopic repair of cerebrospinal fluid fistulae and encephaloceles. Laryngoscope 1996;106(9 Pt 1):1119-1125.

13. Hegazy HM, Carrau RL, Snyderman CH, Kassam A, Zweig J. Transnasal endoscopic repair of cerebrospinal fluid rhinorrhea: a meta-analysis. Laryngoscope 2000;110(7):1166-1172.

14. Jones V, Virgin F, Riley K, Woodworth BA. Changing paradigms in frontal sinus cerebrospinal fluid leak repair. Int Forum Allergy Rhinol 2012;2(3):227-232.
15. Eloy JA, Liu JK, Choudhry OJ, Anstead AS, Tessema B, Folbe AJ, et al. Modified subtotal lothrop procedure for extended frontal sinus and anterior skull base access: a cadaveric feasibility study with clinical correlates. J Neurological Surg. Part B, Skull base 2013;74(3):130-135.

16. Batra PS, Kanowitz SJ, Luong A. Anatomical and technical correlates in endoscopic anterior skull base surgery: a cadaveric analysis. Otolaryngol Head Neck Surg 2010;142(6): 827-831. 